\title{
The Jaundiced Newborn in the Emergency Department: Prevention of Kernicterus
}

\author{
Vinod K. Bhutani, MD, FAAP, ${ }^{*}$ Lois Johnson, MD, FAAP $\dagger$
}

\begin{abstract}
A jaundiced neonate in an emergency department can be a catastrophic emergency that necessitates expeditious care. Progressive and irreversible bilirubin neurotoxicity may be minimized by rapid reduction of serum bilirubin concentrations through a crash-cart approach: immediate administration of intensive phototherapy and preparation for a possible exchange transfusion. Onset of acute bilirubin encephalopathy (ABE) is initially nonspecific and insidious and may progress to irritability, painful tonic spasms, apnea, seizures, obtundation, coma, respiratory failure, and death. Early recognition of hyperbilirubinemia severity can facilitate rapid transition to treatment and overcome the major barriers to timely therapy. Emergency department personnel need to develop policies that define access to intensive phototherapy either on site or immediate access to a neonatal/pediatric critical care facility. This article reviews a systems strategy for a crash-cart approach that may be initiated in the emergency department for a safer transition to alternative facilities to manage and prevent $A B E$.
\end{abstract}

Clin Ped Emerg Med 9:149-159 @ 2008 Elsevier Inc. All rights reserved.

KEYWORDS acute bilirubin encephalopathy, newborn jaundice, crash cart approach, intensive phototherapy, triage for newborn jaundice, severe neonatal hyperbilirubinemia

\section{Clinical Case Report}

The patient is currently a 5-year-old male with hearing loss (that has responded to cochlear implants), choreoathetosis, decidual teeth enamel dysplasia, and upgaze abnormalities. His story begins at birth as a normal healthy newborn. The patient's mother was admitted to a regional hospital at 7:30 $\mathrm{PM}$, and the baby was delivered at 7:26 AM the next day (Thursday). His mother, aged 22 years, Hispanic and non-English-speaking, had blood type $A B$, was Rh-positive, was hepatitis surface antigennegative, and was Rubella-immune. A marginal abruption of the placenta was noted by the obstetrician. Her HIV status was negative.

\footnotetext{
*Stanford University School of Medicine and Lucile Packard Children's Hospital, Stanford, CA.

$†$ Pennsylvania Center for Kernicterus, Philadelphia, PA.

Reprint requests and correspondence: Vinod K. Bhutani, MD, Division of Neonatal and Developmental Medicine, Department of Pediatrics, Stanford University School of Medicine, Lucile Packard Children's Hospital, 750 Welch Ave \#315, Stanford, CA 94304.

(E-mail: bhutani@stanford.edu)
}

At birth, the newborn was noted to be term gestation at 38 weeks and appropriate for gestational age. The Apgar scores were 10 at 1 and 5 minutes. The birth weight was $2715 \mathrm{~g}$, the length was $48.5 \mathrm{~cm}$, and the head circumference was $32.5 \mathrm{~cm}$. The newborn was examined at 8:10 AM, with vitals signs including a pulse rate of $156 / \mathrm{min}$ and a respiratory rate of $36 / \mathrm{min}$. The examination was recorded as normal, and no clinical risk factors were noted. He was admitted to the well baby nursery and declared a stable newborn by a nurse. At age 24 hours (Friday), the skin color was noted as pink. Mother and baby were discharged from the maternity floor at an infant age of about 29 hours. No discharge orders were provided other than to return to see the obstetrician 6 weeks later and to the pediatrician in 2 weeks.

On Sunday, at an infant age of approximately 74 hours, the patient was seen at the emergency department (ED) at the birthing hospital. He was alert, oriented, and conscious, with a heart rate of $160 / \mathrm{min}$, respiratory rate of $39 / \mathrm{min}$, and a temperature of $39^{\circ} \mathrm{C}$. The ED chart lists him as "well," "baby has turned yellow," "good startle reflex" "child jaundiced." The patient's parents left the ED 
before completion of care because they were frustrated with "lack of attention" about 2 hours later. The patient then presented to the ED at the Children's Hospital at age 77 hours. At age 78 hours, the infant was examined by the ED physician and noted to have "good tone." Urine and blood tests were obtained while the infant was "alert and active." The total serum bilirubin (TSB) of $44.1 \mathrm{mg} / \mathrm{dL}$ was reported at age 81 hours. At this time, the infant was "very yellow but alert." The neonatal intensive care unit (NICU) was notified. The infant was admitted to the NICU at age 83 hours. Vital signs upon admission were the following: $\mathrm{HR}=134 / \mathrm{min}, \mathrm{RR}=48 / \mathrm{min}, \mathrm{T}=37.3^{\circ} \mathrm{C}, \mathrm{BP}=$ $71 / 38 \mathrm{~mm} \mathrm{Hg}$ (mean $=58$ ). The infant is now described as having "orange jaundice," was "very icteric," and was "irritable." Between ages 83 and 86 hours, he was noted to be "jittery at times," with "decreased tone in leg," and "when supine infant tend(ed) to turn trunk to head and shoulders and arms to the right and keep lower extremities midline." He was administered phototherapy. Consent for blood exchange transfusion was obtained at age 87 hours.

After discharge from the intensive care nursery, there was no further recurrence of jaundice, and no specific cause for the hazardous hyperbilirubinemia was identified. At age 3 months, auditory brainstem response testing showed sensorineural hearing loss. Examination at age 18 months was consistent with kernicterus.

\section{Lessons Learned From the Case Report}

In this formerly healthy newborn infant's hyperbilirubinemia and acute bilirubin encephalopathy (ABE) experiences, there were multiple lapses in the health care provided during his first 4 days of life (particularly on a weekend). These delays were augmented by absence of an identified and accessible "medical home." We conducted a root cause analysis of this self-referred admission to the ED and other similar cases directed from physician's offices [1]. Lessons from this case are discussed in this article and include the following:

1. Progressive or suddenly recognized jaundice with TSB concentrations $>25 \mathrm{mg} / \mathrm{dL}$ (severe hyperbilirubinemia for term infants) and/or signs of $\mathrm{ABE}$ in newborn infants are medical emergencies.

2. These infants require prompt and immediate implementation of bilirubin reduction strategies that include intensive phototherapy and/or preparation for possible blood exchange transfusion.

3. Transition from progressive hyperbilirubinemia to $\mathrm{ABE}$ is often rapid and unpredictable. There is a very narrow margin of safety, and time matters.

4. Each ED that attends to a neonatal population should have a triage policy to identify infants at risk for $\mathrm{ABE}$ (within 1 to 2 hours of presentation) and a process for direct and prompt transfer to a specialty neonatal/pediatric facility for specific care.
5. Symptomatic jaundiced infants and those with severe hyperbilirubinemia should be directly and promptly referred to neonatal and pediatric intensive care facilities, and in certain centers might even bypass the ED.

\section{Introduction}

Jaundice is the commonest clinical diagnosis in neonatal medicine and is due to elevated unconjugated (indirect) and/or conjugated (direct) bilirubin levels [2]. Confirmation is by a total serum (plasma) blood test for bilirubin (TSB) or transcutaneous bilirubin (TcB). Bilirubin is a known antioxidant at low levels (in vitro) and a potent neurotoxin at high levels (in vivo). Estimated incidence in the United States is tabulated in Table 1 [3]. Elevated bilirubin concentrations may occur due to increased bilirubin production (breakdown of heme moiety of hemoglobin) and/or delayed bilirubin elimination (hepatic and intestinal), as well as, by a unique neonatal phenomenon of enterohepatic reabsorption of bilirubin. Bilirubin and carbon monoxide are the major degradation products of heme. The non-water-soluble unconjugated bilirubin (bound to albumin) is processed in the hepatocyte to the excretable water-soluble-conjugated bilirubin by the enzyme uridine-diphospho-glucuronosyl-transferase (UGT). With decreased gastrointestinal activity and/or starvation in the immediate postnatal period, some of this conjugated bilirubin is reconverted to unconjugated bilirubin in the gut and reabsorbed in the circulation (enterohepatic recirculation). The neurotoxic effect of bilirubin does not correlate well with TSB levels because it is influenced by the ability of unconjugated bilirubin $(\mathrm{mg} / \mathrm{dL})$ to bind with albumin $(\mathrm{g} / \mathrm{dL})$ at ratio of about 8:1. Bilirubin binding to albumin is influenced by acidosis, hypoalbuminemia, lower gestational age, postnatal age (age $<3$ days), and interference by drugs (especially sulfas and some cephalosporins). Neurologic injury, assessed by magnetic resonance imaging, is evident in the basal ganglia (globus pallidus and subthalamic nuclei), brainstem nuclei (especially, auditory, and cochlear nuclei), inferior colli-

Table 1 Current known incidence of severe hyperbilirubinemia in the United States [3].

\begin{tabular}{|c|c|c|}
\hline \multirow{2}{*}{$\begin{array}{l}\text { TSB Levels at Age }>72 \mathrm{~h} \\
>17 \mathrm{mg} / \mathrm{dL}(>95 \mathrm{th} \text { percentile) } \\
\text { significant }\end{array}$} & \multicolumn{2}{|c|}{ Incidence } \\
\hline & $8.1 \%-10 \%$ & 1 in 10 \\
\hline $\begin{array}{l}>20 \mathrm{mg} / \mathrm{dL}(>98 \text { th percentile }) \\
\text { severe in late preterm infants }\end{array}$ & $1 \%-2 \%$ & 1 in 70 \\
\hline $\begin{array}{l}>25 \mathrm{mg} / \mathrm{dL} \text { ( }>99.9 \text { th percentile) } \\
\text { severe }\end{array}$ & $0.16 \%$ & 1 in 700 \\
\hline $\begin{array}{l}>30 \mathrm{mg} / \mathrm{dL}(>99.99 \text { th percentile }) \\
\text { hazardous }\end{array}$ & $0 \%-0.032 \%$ & 1 in 10,000 \\
\hline $\mathrm{ABE}$ & $\begin{array}{l}1 \text { in } 40,000 t \\
\text { live births (e }\end{array}$ & $\begin{array}{l}70,000 \\
\text { timate) }\end{array}$ \\
\hline
\end{tabular}


culus, the cerebellum and the hippocampus (especially the CA2 sector). Acute clinical manifestations of bilirubin neurotoxicity are those of $\mathrm{ABE}$ : progressive changes in infant's cry pattern, muscle tone, apnea, seizures, and behavioral changes. If unmonitored or with delayed treatment, irreversible posticteric sequelae, known as kernicterus, may manifest during infancy. These are characterized by movement disorders of dystonia, athetosis and choreoathetosis, sensorineural hearing loss, oculomotor abnormalities of strabismus, and gaze palsies (especially, upgaze). Kernicterus is one of the most easily preventable forms of neonatal brain damage [2-9].

\section{Predisposing Clinical Risk Factors}

Neonatal jaundice is common, so it is important that clinicians recognize and understand the factors that place infants at increased risk of developing severe hyperbilirubinemia. A predischarge TSB/TcB, plotted on the hourspecific bilirubin nomogram at the time of infant's discharge from the birthing hospital, accurately predicts the postnatal risk of severe hyperbilirubinemia (Figure 1). Infants with bilirubin concentrations in the high-risk zones of the nomogram require a more rigorous and frequent, often daily, follow-up until the bilirubin concentrations decline substantially [1].

Common clinical predisposing factors include those that aggravate hemolysis, promote functional immaturity of the liver, or delay elimination and are outlined in Table 2 $[10,11]$. Red blood cell breakdown occurs from a number of conditions in newborns and increases the risk of severe hyperbilirubinemia. Infants with $\mathrm{ABO}$ or Rh blood group incompatibilities may develop severe hyperbilirubinemia within the first 24 hours after birth. Increased hemolysis results from maternal antibodies reacting with fetal and neonatal antigens. Rh incompatibilities may occur when the infant is Rh-positive and the mother is Rh-negative. With the introduction of Rh immunoglobin in the 1960s, the incidence of $\mathrm{Rh}$ incompatibility dropped significantly. Today, $\mathrm{ABO}$ incompatibilities have become the main blood group incompatibility. $\mathrm{ABO}$ incompatibilities may occur when the infant has type $A, B$, or $A B$ blood and the mother has type $\mathrm{O}$. Less frequently, incompatibility of minor group blood types may lead to significant hemolysis. Glucose6-phosphate dehydrogenase (G6PD) deficiency is also frequently associated with neonatal hyperbilirubinemia. Although increased hemolysis may clearly contribute to

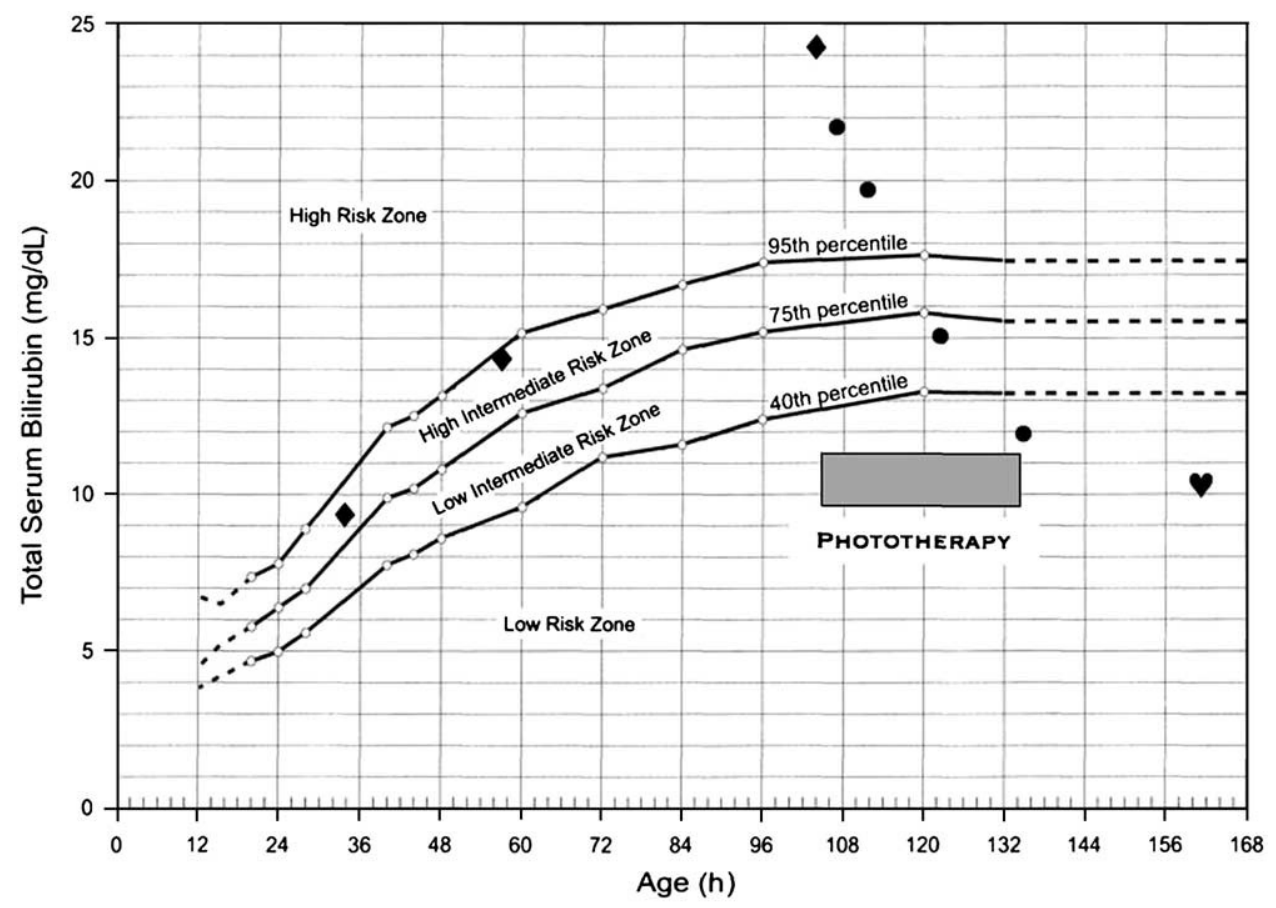

Figure 1 Serial values of TSB before $(\bullet)$, during $(\bullet)$, and subsequent $(\bullet)$ to intensive phototherapy in a late preterm (36 and 4/7 weeks gestational age) infant with a birthweight of $3840 \mathrm{~g}$ and discharged at age 37 hours, as shown on a hour-specific bilirubin nomogram [2]. He was seen in the pediatrician's office the next day. On Sunday morning, the family was concerned about the infant's color and poor feeding. He was brought to the birthing hospital ED. Within an hour, he was transferred to the NICU, placed under intensive phototherapy, and initiated on an intravenous fluid correction for dehydration. An automated auditory brainstem response was abnormal in the right ear. Clinical signs of lethargy and irritability with a normal muscle tone were consistent with a diagnosis of early ABE. Preparations were made for an exchange transfusion. Within 3 hours, there was a substantial decline in the TSB concentration. The repeat automated auditory brainstem response within 4 hours of treatment was normalized. Infant had done well on long-term follow-up at age 18 months. (Nomogram reprinted with permission.) 
Table 2 Some of the common causes for neonatal hyperbilirubinemia [11].

\begin{tabular}{|c|c|}
\hline Biological Basis & Clinical Conditions \\
\hline $\begin{array}{l}\text { Increased bilirubin } \\
\text { production }\end{array}$ & $\begin{array}{l}\text { 1. Isoimmunization-Rh, ABO, and minor group incompatibilities } \\
\text { 2. RBC enzyme defects-G6PD deficiency, pyruvate kinase deficiency, hexokinase deficiency; } \\
\text { congenital erythropoietic porphyria; etc } \\
\text { 3. RBC structural defects-hereditary spherocytosis (autosomal dominant; especially if } 1 \text { parent has } \\
\text { splenomegaly or had splenectomy); hereditary elliptocytosis; infantile pyknocytosis } \\
\text { 4. Sepsis-bacterial; viral (such as CMV); protozoal } \\
\text { 5. Extravasated blood-bruising, cephalohematoma, subgaleal bleed, subdural hematoma, } \\
\text { hemangiomas } \\
\text { 6. Polycythemia }\end{array}$ \\
\hline $\begin{array}{l}\text { Increased enterohepatic } \\
\text { circulation }\end{array}$ & $\begin{array}{l}\text { 1. Prematurity } \\
\text { 2. Starvation } \\
\text { 3. Decreased gastrointestinal activity } \\
\text { 4. Delayed bacterial colonization of the gut } \\
\text { 5. Pyloric stenosis, GI immotility or obstruction }\end{array}$ \\
\hline Decreased elimination & $\begin{array}{l}\text { 1. Crigler-Najar syndrome: (type } 1 \text { UGT)—autosomal recessive, diagnose by liver biopsy } \\
\text { 2. Gilbert syndrome: neonatal variant often confused as breast milk jaundice. Sometimes } \\
\text { coinherited with G6PD deficiency } \\
\text { 3. Arias syndrome (type II UGT)—autosomal dominant with variable penetrance } \\
\text { 4. Transient familial neonatal hyperbilirubinemia (Lucey-Driscoll) syndrome—rare, caused by } \\
\text { inhibitor of UGT from mother }\end{array}$ \\
\hline
\end{tabular}

Abbreviations: RBC, red blood cell; CMV, cytomegalovirus; GI, gastrointestinal; UGT, uridine-diphospho-glucuronosyl-transferase; G6PD, glucose-6-phosphate dehydrogenase.

the hyperbilirubinemia in some G6PD-deficient populations, in other populations, decreased conjugation is the main contributor to hyperbilirubinemia.

Decreased bilirubin conjugation, the result of a variant promoter for the gene UGTIAl encoding the B-UGT enzyme (as seen in Gilbert's syndrome), has been shown to contribute significantly to the development of hyperbilirubinemia in neonates with the Mediterranean type of G6PD deficiency. Thus, it is likely that G6PD-deficient neonates who develop bilirubin toxicity have a combination of increased bilirubin production rates and the variant UGT1Al promoter gene that diminishes the capacity for bilirubin conjugation. Presently, neonatal screening for G6PD deficiency is not routine. Evaluation for G6PD deficiency needs to be considered among infants with progressive hyperbilirubinemia and ethnic or racial risk factors and, those infants who respond poorly to phototherapy. The G6PD enzyme deficiency should be suspected in any infant with unexplained severe hyperbilirubinemia or in those from regions including South and Eastern Asia, African coasts, the Mediterranean, and parts of the Middle East. Population migrations and multiracial ancestry have changed the global patterns of G6PD deficiency. History of exposure to agents that trigger a hemolytic reaction (such as mothballs, fava beans, antimalarial drugs) should be elicited from mothers of known G6PD carriers or from those who are at risk because of ethnicity or race.

Perinatal factors can increase an infant's risk for developing hyperbilirubinemia. Bruised infants and those with a cephalohematoma are more likely to experience hyperbilirubinemia due to increased red cell break down. Pitocin has been linked to hyperbilirubinemia, although the mechanism underlying this relationship is not clearly understood. Infants with perinatal sepsis and asphyxia are more vulnerable to bilirubin toxicity and neuronal susceptibility at lower concentrations of bilirubin.

Breast-feeding and its association with newborn jaundice are complex. An evidence-based review of issues surrounding neonatal hyperbilirubinemia found that among the identified cases of kernicterus, almost all of the infants were breast-fed. Root cause analysis of lactation failure in infants with kernicterus identified inadequate (a) clinician-initiated education, (b) on-site certified consultants, (c) documentation of infant latching, $(d)$ measure of milk transfer, and (e) follow-up and record of urine and stool pattern changes. Thus, a suboptimal lactation experience and exclusive breast-feeding may be considered as a predictive risk factor for hyperbilirubinemia. Inadequate intake and dehydration slow bilirubin elimination and increase enterohepatic circulation. Conversely, good milk transfer and infant weight gain are reassuring signs in a breast-fed infant and suggest that severe hyperbilirubinemia is less likely to occur. Approximately $20 \%$ to $40 \%$ of women have a high level of $\beta$-glucoronidase in their breast milk that may potentiate hyperbilirubinemia by increasing enterohepatic circulation of bilirubin. However, this is an area that requires further investigation because some studies have not found increased $\beta$-glucoronidase levels present in breast-fed infants with hyperbilirubinemia. A population-based study demonstrated that bilirubin levels for appropriately breast-fed infants are only marginally higher than those in exclusively formula fed infants.

Late preterm gestation infants born between 34 and 36 and $6 / 7$ weeks of gestation are at high risk of severe 
Table 3 Clinical risk factors for severe neonatal hyperbilirubinemia [2].

\begin{tabular}{ll}
\hline Risk Factors & Assessment \\
\hline Major & \\
1. Predischarge TSB/TcB & Laboratory \\
>95th percentile & test \\
2. Jaundice at age $<24 \mathrm{~h}$ & Clinical \\
& observation \\
3. Blood group incompatibility & Laboratory \\
& test \\
4. Gestational age 35-36 wk & Clinical \\
& examination \\
5. Sibling received phototherapy & History \\
6. Cephalohematoma or significant & Clinical \\
bruising & examination \\
7. Exclusive but suboptimal & History and \\
breast-feeding & observation \\
8. East Asian race & History \\
Minor & \\
9. Predischarge TSB/TcB: & Laboratory \\
75th-95th percentile & test \\
10. Gestational age $37-38$ wk & Clinical \\
11. Jaundice observed before & examination \\
discharge & Observation \\
12. Sibling with jaundice & \\
13. Macrosomic infant of a diabetic & History \\
mother & History \\
14.Maternal age $\geq 25$ y & \\
15. Male sex & Examination \\
\hline & History \\
\hline
\end{tabular}

hyperbilirubinemia, dehydration, and ABE. In California, they account for nearly $25 \%$ of the readmissions for healthy infants during the first month of age. The risk for bilirubin neurotoxicity occurring at lower levels of hyperbilirubinemia has been attributed to lower albumin levels and immature livers that are less able to eliminate bilirubin. Infants with diminished albumin binding sites are at risk for bilirubin neurotoxicity [12]. The 2004 American Academy of Pediatrics (AAP) guidelines provide a listing of major and minor clinical risk factors for severe hyperbilirubinemia (Table 3). Of these, gestational immaturity and the predischarge TSB/TcB are the best predictors [13].

\section{Recognition and Follow-Up of Jaundice}

Jaundice is recognized by blanching the skin over the forehead, sternum, hip, knees and ankles with digital pressure to reveal the underlying skin and subcutaneous tissue color. Skin color varies from healthy pink, lemony yellow, to orange and sienna. Assessment is limited by skin pigmentation, plethora, decreased ambient light, and prior exposure to sun or phototherapy. Melanin skin pigmentation is variable among individuals and is influenced by ancestry, ethnicity, and individual responses to sunlight exposure. If jaundice cannot be clearly excluded, one may assess the mucosal areas such as the gum margins. Yellow coloration of the sclera, usually evident in adults, is often a late observation in newborn infants. It is often difficult to visualize the sclera during the first few days after birth. Progression of recognition of jaundice may be cephalocaudal or it can fade in and out like a tan. It is important that clinicians do not estimate severity of hyperbilirubinemia based on skin color; several studies have confirmed the inability of the human eye to accurately predict the level of bilirubinemia based on skin color [14].

\section{Risk of Bilirubin Neurotoxicity}

Clinical risk factors for neurotoxicity include prematurity, asphyxia, sepsis, hypoalbuminemia, lethargy, and temperature instability. The neonatal brain has a unique blood-brain barrier that slows the equilibrium between plasma and brain and is generally protective. When the blood-brain barrier is intact, as in the healthy newborn, the rate of bilirubin uptake by the brain is likely to be determined by the (1) concentration of unbound bilirubin, (2) structural and genetic vulnerability of the brain, (3) duration of exposure, (4) ability of bilirubin to bind to albumin, and (5) local cerebral blood perfusion. In healthy late-preterm and term infants, the risk of bilirubininduced neuronal injury is related to the concentration of unbound or "free" unconjugated bilirubin and hydrogen ions (pH) in the blood. "Free" unconjugated bilirubin occurs when the albumin binding capacity is exceeded or when other displacing substances compete for bilirubin binding sites on albumin. If the blood-brain barrier is disrupted, as can occur in infants who are sick, asphyxiated, or who have experienced brain hemorrhage, bilirubin bound to albumin can move rapidly into the extracellular space in the brain. When the concentration of unbound bilirubin is high, entry of bilirubin into neuronal cells can produce a sequence of cellular events that may lead to neurotoxicity and ultimately to cell death. However, because the injurious effects of bilirubin on neuronal cells depend on both duration and magnitude of the exposure, it is possible that minimal harmful exposure may be reversed. The extent to which cellular defense mechanisms contribute to variations of toxic effects of bilirubin remains uncertain [15].

\section{Acute Bilirubin Encephalopathy}

The neurotoxic effects of bilirubin can lead to ABE. Because the earliest signs of $\mathrm{ABE}$ are subtle and nonspecific, they may be missed. The classic signs of $\mathrm{ABE}$ are increasing hypertonia, especially of extensor muscles with retrocollis and opisthotonos, in association with varying degrees of drowsiness; poor feeding; hypotonia; alternating tone; and high-pitched or absent cry. These signs can be described in terms of the infant's mental status, muscle tone, and cry [16]. Signs of ABE should be determined by close clinical observation and by direct questioning of parents. The rate of progression of clinical signs depends on the rate of bilirubin rise, the duration of 
hyperbilirubinemia, the adequacy of albumin binding reserves, the level of unbound bilirubin, host susceptibility, and the presence of comorbidities. Prompt and effective intervention when $\mathrm{ABE}$ symptoms appear can prevent chronic kernicteric sequelae. A combination of intensive phototherapy and exchange transfusion may be used to rapidly reduce the bilirubin load and potentially the extent of brain damage. Late signs of $A B E$ include cessation of feeding, bicycling movements, inconsolable irritability and crying, respiratory failure, progressive coma, or intractable seizures. The likelihood of kernicteric sequelae is increased when late signs are present. Acute bilirubin encephalopathy may also lead to death after respiratory failure, apnea, seizures, and/or coma. Clinical risk factors for bilirubin neurotoxicity are used as guidelines to tailor the bilirubin thresholds for initiation of intensive phototherapy and are useful to manage an infant until the availability and validation of objective tests such as the unbound bilirubin and auditory brainstem responses can be obtained. Overall, current laboratory and clinical data indicate "bilirubin damages brain tissue cells via necrosis and apoptosis, either alone or in combination, in a neuroanatomic distribution dependent on the amount, duration, and developmental timing of exposure of sensitive brain tissue to free bilirubin." As described by Shapiro [17], "the extent of neuronal injury depends on (1) the amount and duration of exposure to free bilirubin (high level, short duration exposure not necessarily the same as lower level, long duration exposure), (2) the susceptibility of the developing nervous system, (3) the relative amount of necrosis vs apoptosis produced, and (4) whether surviving neurons will be functionally normal or more susceptible to other stressors either at the time of hyperbilirubinemia or afterwards."

\section{Timing of Interventions to Reduce Excessive Bilirubin Load}

Is the outcome of an infant with $\mathrm{ABE}$ different if phototherapy and/or exchange transfusion is provided sooner? The timing of bilirubin reduction strategies impacts the outcome of severe hyperbilirubinemia complicated by ABE. Early implementation of strategies to rapidly and effectively reduce the excessive bilirubin load before the onset of neurologic signs, in all likelihood, would prevent chronic posticteric sequelae or kernicterus [18]. Once the clinical signs of bilirubin neurotoxicity are evident, emergent intervention to expeditiously reduce the bilirubin load is the only known recourse in clinical practice. To date, exchange transfusion remains the only known clinical option. Although there is no predictive evidence that a specific bilirubin level will or will not cause neurotoxic damage, the critical bilirubin level, in

Table 4 Steps for a crash-cart approach to manage hazardous hyperbilirubinemia [8].

\begin{tabular}{|c|c|}
\hline Options & Most Effective Means to Minimize Brain Damage \\
\hline Assess risk (triage management) & $\begin{array}{l}\text { 1. Rapid clinical examination to check (a) severity of jaundice, (b) TcB test, } \\
\text { (c) neurologic examination for muscle tone, behavior, and cry pattern. } \\
\text { 2. Plot TcB and recent TSB level on the AAP bilirubin nomogram for risk assessment } \\
\text { and for exchange transfusion. [2] } \\
\text { 3. Weigh against the potential risk of ABE and timeliness/safety of interventions } \\
\text { (experience is essential). } \\
\text { 4. Communicate with families regarding potential of imminent risk. }\end{array}$ \\
\hline $\begin{array}{l}\text { Laboratory tests (do not wait for results } \\
\text { to start phototherapy) }\end{array}$ & $\begin{array}{l}\text { TSB and direct bilirubin level, serum albumin, serum electrolytes } \\
\text { Blood type (ABO, Rh), direct antibody test (Coombs') } \\
\text { CBC, differential and smear for cell morphology; reticulocyte count } \\
\text { G6PD enzyme assay (quantitative) } \\
\text { Urine for reducing substances and other tests: as needed }\end{array}$ \\
\hline Immediate Interventions & $\begin{array}{l}\text { Start intensive phototherapy (while procedures are being done). } \\
\text { Consider immune globulin (IVIG) for isoimmune hemolytic disease. } \\
\text { Albumin infusion }(1 \mathrm{~g} / \mathrm{kg} \text { ) for hypoalbuminemia }(<3 \mathrm{~g} / \mathrm{dL} \text { ) just before exchange } \\
\text { transfusion has been used but concerns remain of its safety. }\end{array}$ \\
\hline Definitive procedure & $\begin{array}{l}\text { Isovolume double volume exchange }(170 \mathrm{~mL} / \mathrm{kg} \text { in term, } 190 \mathrm{~mL} / \mathrm{kg} \text { in preterm). } \\
\text { Indications: For presence or onset of any neurologic signs, failed automated auditory } \\
\text { brainstem response, if TSB approaches exchange threshold or bilirubin }(\mathrm{mg}) \text { to } \\
\text { albumin }(\mathrm{g}) \text { ratio is }>7 \mathrm{(mg} / \mathrm{g}) \text { or failure of intensive phototherapy to substantially } \\
\text { reduce TSB levels. }\end{array}$ \\
\hline Duration of procedure & $\begin{array}{l}\text { Exchange transfusion may be accomplished within } 3 \text { to } 4 \text { hours (informed consent, } \\
\text { laboratory evaluation, central catheters and access and other procedures). } \\
\text { Ideal location: neonatal/pediatric intensive care facility. }\end{array}$ \\
\hline Technical problems & $\begin{array}{l}\text { A single volume exchange transfusion may be adequate while intensive } \\
\text { phototherapy is being delivered. }\end{array}$ \\
\hline
\end{tabular}


any healthy baby, is influenced by postnatal age, maturity within the range of term gestational age, duration of hyperbilirubinemia, and rate of TSB rise. Hansen [19] and Watchko [20] have recently summarized the scientific evidence and mechanism of bilirubin neurotoxicity. These indicate that bilirubin kills specific neurons by causing necrosis; in vitro studies show that it induces apoptosis and support in vivo observations in older literature showing neuroanatomic changes consistent with apoptosis. Evidence also suggests that bilirubin interferes with intracellular calcium homeostasis by altering function and expression of calcium/calmodulin kinase II, by selectively decreasing calcium-binding proteins in susceptible brainstem areas and increasing intracellular calcium in cultured neurons, and by sensitizing the cell to other injuries or triggering apoptosis. Bilirubin may also kill cells by causing neuronal hyperexcitability, perhaps via excitatory amino acid neurotoxicity, or it may have other membrane or neurotransmitter effects. Finally, it may act by interfering with mitochondrial respiration and energy production. Thus, interventions that reduce bilirubin exposure to the neonatal brain have been shown to prevent bilirubin neurotoxicity. The timing of interventions does matter.

\section{Crash-Cart Management for Hazardous Hyperbilirubinemia and $A B E$}

An infant presenting with signs of $A B E$ or with bilirubin levels that exceed thresholds for severe hyperbilirubinemia requires urgent and expert attention [8,21,22]. A clinical algorithm [22] may be used to guide the efforts of the ED care team (Table 4) to coordinate the ensuing interventions that will appear to be suddenly invasive and intrusive to a family that was just at home and celebrating a birth. To prevent permanent sequelae, the acute evaluation and interventions need to be implemented in a matter of couple of hours (Figure 2). If the TSB level is approaching or is at hazardous levels or onset of $\mathrm{ABE}$ is recognized, the goal of therapy is to dramatically reduce the bilirubin load, promptly, safely, and expeditiously.

\section{Triage for a Jaundiced Newborn Arriving at the ED}

The triage process should be guided by ongoing staff clinical education, development and implementation of a local protocol, and action plan (Figure 2). The key components follow:

1. Supplies_— there must be ready access to devices, equipment, and a transport isolette.

2. Clinical assessment- - this should identify risk factors and include a rapid neurologic examination.

3. Testing_— TcB testing and other STAT laboratory studies (if essential).

4. Informed consent—one must advise the parents of the medical emergency.
5. Treatment—initiate intensive phototherapy (or transfer for therapy) within about an hour of arrival.

\section{Emergency Interventions for Rapid Reduction of Bilirubin Concentrations}

Rapid bilirubin reduction strategies include intensive phototherapy, double volume blood exchange transfusion, and the occasional need for pharmacologic agents, often used in combination. Once progressive ABE has occurred, there are no neuroprotective agents that have been investigated; thus, prevention remains the key strategy. Brief descriptions of emergency interventions are provided here, and the reader is referred to detailed sources for implementation materials.

\section{Intensive Phototherapy}

Phototherapy is the current intervention of choice to reduce the severity of neonatal unconjugated hyperbilirubinemia, regardless of its etiology, in a matter of 2 to 4 hours [2]. Optimal use of phototherapy has been defined by specific ranges of TSB thresholds that have been configured to an infant's postnatal age (in hours) and potential risk for bilirubin neurotoxicity. Effective phototherapy implies its use as a "drug" with specific blue light wavelengths at a specific peak wavelength $(460 \mathrm{~nm})$ and a range of emission spectrum (400-520 nm), preferably in a precise (narrow) bandwidth that is delivered at an irradiance (dose) of $\geq 30$ to $35 \mu \mathrm{W} / \mathrm{cm}^{2}$ per nanometer to $80 \%$ of an infant's body surface area (BSA). There are several commercial devices and delivery methods for phototherapy for use at both the hospital and home. Blue lights in the 425 to $475 \mathrm{~nm}$ range (Phillips F-20 T12/BB or NeoBlueTM) should be easily and rapidly accessible and periodically inspected and maintained to ensure proper functioning. These may be complemented with white halogen lights to cover a wider surface area; avoid shadows created with multiple lights. Clinical response to a specific modality is also dependent on a number of factors that include ongoing rate of bilirubin production, maturation of enterohepatic elimination processes, performance of the device, and operational barriers to effective administration. The efficacy is additionally influenced by $(a)$ optimization of light administration to achieve a minimum distance between the device and the patient such that the foot print of light covers maximum BSA with minimal physical barriers; (b) infant characteristics such as the severity of jaundice, BSA proportions, as well as dermal thickness, pigmentation, and perfusion; $(c)$ the duration of treatment to a specific bilirubin threshold. As described by Maisels and McDonagh [23], "the absorption of light by the normal form of bilirubin (4Z,15Z-bilirubin) generates transient excited-state bilirubin molecules. These fleeting intermediates can react with oxygen to produce colorless products of lower molecular weight, or they can undergo rearrangement to become structural isomers (lumirubins) or 


\section{Triage Algorithm: Well-appearing Jaundiced Neonate}
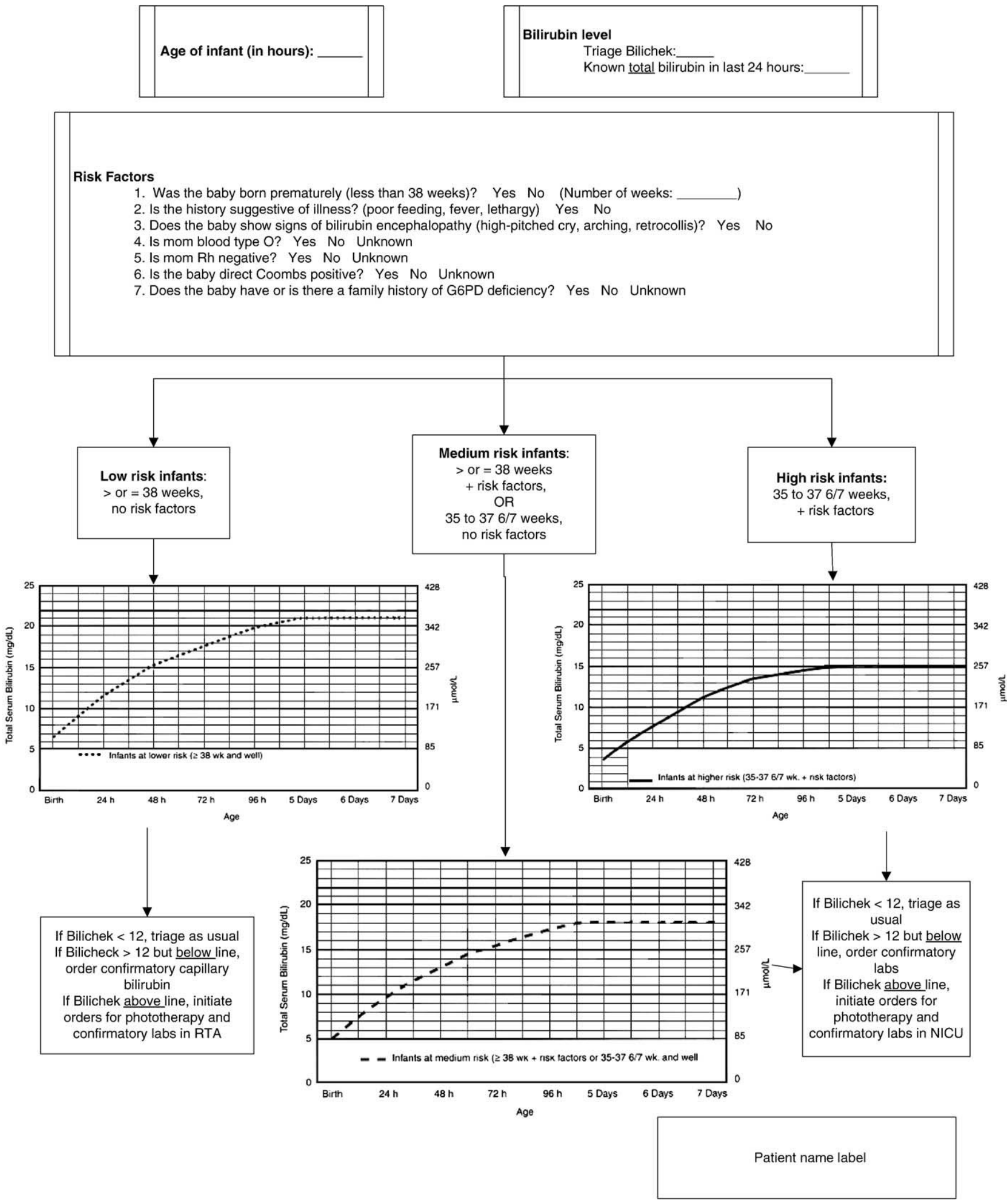

Figure 2 An algorithm for ED management as proposed by Smitherman et al [22] (reprinted with permission). 
isomers in which the configuration of at least one of the 2 Z-configuration double bonds has changed to an E configuration. Isomerization processes occur more quickly than photooxidation. Phototherapy converts bilirubin to yellow photoisomers and colorless oxidation products that are less lipophilic than bilirubin and do not require hepatic conjugation for excretion. Photoisomers are excreted mainly in bile and oxidation products predominantly in urine. Sunbathing is no longer recommended in newborn infants as a means to treat jaundice [23].

\section{Exchange Transfusion}

Exchange transfusion is a critical and invasive procedure that can significantly reduce a bilirubin level in a matter of 1 to 2 hours [2]. Trained personnel in neonatal/pediatric intensive care facilities with full monitoring and resuscitation capabilities should perform this procedure. Exchange transfusion should be considered and anticipated when there are signs of ABE (even if TSB is falling) or if there are significant concerns of neurotoxicity. Concerns for neurotoxicity are heightened in an asymptomatic infant when (a) the TSB level exceeds $30 \mathrm{mg} / \mathrm{dL}$; (b) intensive phototherapy fails to produce a significant TSB reduction in an infant with severe hyperbilirubinemia (a progressive TSB decline of at least $>0.5 \mathrm{mg} / \mathrm{dL}$ per hour or $>2 \mathrm{mg} / \mathrm{dL}$ drop in 4 hours should be expected); or (c) an infant who had an earlier successful hearing screen and fails an automated auditory brainstem response screen. Before an exchange transfusion is initiated, the health care team should review the risks and benefits of the procedure with the parents, so they can provide informed parental consent. The adverse effects of an exchange transfusion include neonatal morbidities such as apnea, anemia, thrombocytopenia, electrolyte and calcium imbalance, risk of necrotizing enterocolitis, hemorrhage, infection, complications related to the use of blood products, and catheterrelated complications. Exchange transfusion also carries the risk of neonatal mortality, especially in sick infants.

\section{Pharmacologic Options}

Pharmacologic options and chemoprevention strategies have been reviewed in recent articles $[2,8,10,11,24]$. Pharmacologic interventions have a limited role in the ED management of a sick infant. Possible interventions and their usefulness and limitations are briefly discussed.

Albumin Infusion. At times, an albumin infusion $(1 \mathrm{~g} / \mathrm{kg})$ is considered before an exchange transfusion, especially if serum albumin is low $(<3 \mathrm{~g} / \mathrm{dL})$, or immune globulin (IVIG) may be administered when the hyperbilirubinemia is attributed to isoimmunization. Exchange transfusion is performed as an isovolumic procedure, preferably with concurrent withdrawal from an arterial line and infusion through a venous line. Double volume exchange (170 mL/kg) is ideal, but in the event of technical difficulties, a single volume exchange transfusion may be adequate if supplemented with intensive phototherapy. The entire process should be accomplished within 4 to 6 hours of the identification of the medical emergency [2] .

Intravenous Gamma Globulin. For infants with severe hyperbilirubinemia due to blood group incompatibilities, administration of IVIG (0.5-1 g/kg over 2 hours) is recommended if the TSB is rising despite intensive phototherapy or if the TSB is within 2 to $3 \mathrm{mg} / \mathrm{dL}$ ( $34-51 \mu \mathrm{mol} / \mathrm{L}$ ) of the exchange level. If necessary, this dose can be repeated in 12 hours. Intravenous gamma globulin has been shown to reduce the need for exchange transfusions in $\mathrm{Rh}$ and $\mathrm{ABO}$ hemolytic disease. Although data are limited, it is reasonable to assume that IVIG will also be helpful in the other types of $\mathrm{Rh}$ hemolytic disease such as anti-C and anti-E.

Phenobarbital. Phenobarbital can accelerate bilirubin excretion by increasing hepatic clearance. However, this drug is no longer recommended because it has limited or no clinical effect when administered to infants less than 32 weeks of gestation and is ineffective when given before 12 hours of age. The adverse effects of this therapy include sedation, risk of hemorrhagic disease, and the potentially addictive nature of phenobarbital. This drug has a slow onset of effect (usually several days) and a long duration of action ( 1 to 2 weeks) after its discontinuation. For all of these reasons, the use of phenobarbital is no longer recommended.

Tin Mesoporphyrin. Stannic porphyrins, in particular tin mesoporphyrin, inhibit the enzyme heme oxygenase and block the transformation of heme to biliverdin and bilirubin and have been noted to cause photosensitization (especially with intense white light phototherapy). Tin mesoporphyrin has been investigated in clinical pharmacologic and toxicological studies and is effective in reducing bilirubin levels in infants at risk for severe hyperbilirubinemia with no significant side effects. Most infants do not need further phototherapy after tin mesoporphyrin is administered. Tin mesoporphyrin is currently being evaluated for safety, and the Food and Drug Administration has not yet approved its use in the United States.

Other strategies that warrant further investigation and clinical trials are use of agents that interrupt the enterohepatic circulation and bilirubin accumulation from the continued action of $\beta$-glucoronidase. Chemoprevention with use of casein supplements or other agents such as L-aspartic acid could decrease intestinal reabsorption of bilirubin and may play a potential preventive or adjunctive clinical role.

\section{Supportive Interventions}

The first repeat TSB level should be checked within 2 to 4 hours of initiation of therapy to document a substantial response in TSB level. It should be repeated every 3 to 4 hours if TSB is rising and 8 to 12 hours if declining. If there is evidence of dehydration (serum sodium $>153 \mathrm{mEq} /$ $\mathrm{L}$ and/or weight loss $>15 \%$ of birthweight), enteral milk intake, with expressed breast milk, should continue unless the infant is undergoing an exchange transfusion. 
Parenteral fluids should be administered for dehydration or when oral intake is in question. Continuous and uninterrupted intensive phototherapy is recommended until TSB levels decline substantially. Breast-feeding may be resumed after TSB has declined. Phototherapy may be interrupted briefly to facilitate breast-feeding.

\section{Follow-up of Infants with Severe Neonatal Hyperbilirubinemia}

Posticteric sequelae are often unrecognized, mislabeled, or misdiagnosed. These errors have led to prolonged diagnostic and health-seeking odysseys for families [25,26]. Because such presentations to the ED are uncommon, it may be useful to initiate an internal root cause analysis (Table 5) to look for opportunities to improve local practices. Infants with TSB levels greater than $25 \mathrm{mg} / \mathrm{dL}$ and those who receive an exchange transfusion should be followed through infancy until school age for awkward- ness, gait abnormality, failure of fine stereognosis, gaze abnormalities, poor coordination, and exaggerated extrapyramidal reflexes. Follow-up should include neurologic and neurodevelopmental evaluation, neuroimaging with magnetic resonance imaging, and auditory evoked brainstem responses. Prior inattention to quality of care to newborn jaundice and kernicterus has led this newborn condition to be a public health issue [27-29]. Information for parents and health providers is available at the Center for Disease Control and Prevention Web site [30].

\section{Summary}

Severe hyperbilirubinemia and $\mathrm{ABE}$ are continuing risks for infants born in the United States and also for those discharged as healthy from their birth hospital. Because the margin of safety between a specific TSB level and the onset of $A B E$ is narrow and often unpredictable, prevention of $\mathrm{ABE}$ is the only safe medical option. Awareness, recognition, and identification of the subtle neurologic signs in

Table 5 Review of antecedent events for a case of near-miss kernicterus referred to an ED that way cared for by multiple providers at multiple sites.

\begin{tabular}{|c|c|c|c|}
\hline Age & Site & Health Related Events & Potential Opportunities \\
\hline Birth & Birthing Hospital & $\begin{array}{l}\text { Primigravida, Spanish-onlyspeaking mom. } \\
\text { She had chosen to breast-feed. }\end{array}$ & $\begin{array}{l}\text { Mom had prenatal care at an antenatal clinic and } \\
\text { seen for follow-up at the clinic (close to home). }\end{array}$ \\
\hline $33 \mathrm{~h}$ & Birthing Hospital & $\begin{array}{l}\text { Routine Tbili: } 7.3 \mathrm{mg} / \mathrm{dL} \text { (low-intermediate } \\
\text { risk zone) }\end{array}$ & $\begin{array}{l}\text { 1. Prenatal meeting with pediatric staff to outline } \\
\text { the first week postnatal plan of actions. }\end{array}$ \\
\hline $60 \mathrm{~h}$ & Birthing Hospital & $\begin{array}{l}\text { Discharged; follow-up appointment made } \\
\text { at Birthing Hospital clinic }\end{array}$ & $\begin{array}{l}\text { 2. Birthing hospital and clinic to create a } \\
\text { coordinated process for transfer of health } \\
\text { information within } 48 \mathrm{~h} \text { of birthing. }\end{array}$ \\
\hline $5 d$ & $\begin{array}{l}\text { Birthing Hospital } \\
\text { clinic }\end{array}$ & No-show at office visit & $\begin{array}{l}\text { 3. Clinic/Birthing hospital to track no-show } \\
\text { patients for first scheduled appointment within } \\
2 \text { to } 3 \mathrm{~d} \text { of birthing hospital discharge }\end{array}$ \\
\hline $8 \mathrm{~d}$ & $\begin{array}{l}\text { Medical Home \# } \\
\text { first visit }\end{array}$ & $\begin{array}{l}\text { First postbirthing appointment made by } \\
\text { front office staff when infant was } 3 \mathrm{~d} \text { old }\end{array}$ & $\begin{array}{l}\text { 4. Front-office education: front office to verify } \\
\text { nature of appointment and target scheduling for } \\
\text { appointments at age } 3 \text { to } 5 \mathrm{~d} \text {. }\end{array}$ \\
\hline \multicolumn{4}{|c|}{ Age $8 \mathrm{~d}$ : chronological events } \\
\hline $10: 30$ AM & $\begin{array}{l}\text { Medical Home \# } \\
\text { first visit }\end{array}$ & $\begin{array}{l}\text { Examined by family nurse practitioner. } \\
\text { TSB ordered and parents requested to } \\
\text { await instructions. }\end{array}$ & $\begin{array}{l}\text { 5. Recognition of jaundice severity (including } \\
\text { TcB measurements) } \\
6 \text {. Optimize infant blood sample and request for } \\
\text { urgent results (optimal sample to result interval } \\
\text { being }<2 \mathrm{~h} \text { ) }\end{array}$ \\
\hline 1:00 PM & $\begin{array}{l}\text { Medical Home \# } \\
\text { first visit }\end{array}$ & Parents return home, frustrated with wait & $\begin{array}{l}\text { 7. Parents to receive education about jaundice. } \\
\text { 8. MD to review clinical assessment before } \\
\text { infant leaving premises without intervention. }\end{array}$ \\
\hline 3:30 PM & Home & $\begin{array}{l}\text { Parents called with results and asked to } \\
\text { return to pick up referral slip }\end{array}$ & $\begin{array}{l}\text { 9. Direct parents to NICU } \\
\text { 10. Fax referral to health care site (NICU) }\end{array}$ \\
\hline 5:30 PM & $\begin{array}{l}\text { Referral Hospital } \\
\text { NICU }\end{array}$ & $\begin{array}{l}\text { Parents arrive at Referral Hospital } \\
\text { with a slip that states his TSB is } \\
20 \mathrm{mg} / \mathrm{dL} \text {; referred by } \mathrm{RN} \text { to the ED }\end{array}$ & $\begin{array}{l}\text { 11. Clinic and Hospital staff awareness of process } \\
\text { for direct admission to NICU for specific neonatal } \\
\text { emergencies: fever, jaundice, sepsis, } \\
\text { hypoglycemia, shock, and heart defects. }\end{array}$ \\
\hline $\begin{array}{l}\text { 6:30 PM } \\
-10: 00 \text { PM }\end{array}$ & $\begin{array}{l}\text { Referral Hospital } \\
\text { ED }\end{array}$ & Waiting in the ED (no medical care) & $\begin{array}{l}\text { 12. Triage and treatment policies for neonates } \\
\text { arriving to any ED }\end{array}$ \\
\hline 10:30 PM & $\begin{array}{l}\text { Referral Hospital } \\
\text { NICU }\end{array}$ & Admitted to NICU & $\begin{array}{l}\text { Baby admitted with acute kernicterus. } \\
\text { Responded to intensive phototherapy with } \\
\text { rapid reversal of signs for } A B E \text {. }\end{array}$ \\
\hline
\end{tabular}


any infant with severe jaundice and/or hyperbilirubinemia are crucial to a successful outcome. Current evidence suggests that $\mathrm{ABE}$ is reversible with timely, rapid, and effective bilirubin reduction strategies in its early and intermediate phases. Infants with hazardous hyperbilirubinemia and ABE treated with intensive phototherapy and an exchange transfusion in a timely and prompt manner have escaped long-term neurologic sequelae. Thus, in an infant with $\mathrm{ABE}$, rapid, timely, and effective reduction of total bilirubin load could influence long-term outcome.

\section{Acknowledgments}

The work for this article was also supported in part by funds from the Sandy Eglin Fund and her generous support of the Pilot Kernicterus Registry at Pennsylvania Hospital, Philadelphia. This study was supported in part by AAMC/CDC PERT grant MM-0448.

\section{References}

1. Johnson L, Brown AK, Bhutani VK. System-based approach to management of neonatal jaundice and prevention of kernicterus. J Pediatr 2002;93:488-94.

2. American Academy of Pediatrics. Clinical practice guideline: management of hyperbilirubinemia in the newborn infant 35 or more weeks of gestation. Pediatrics 2004;114:297-316.

3. Bhutani VK, Johnson LH, Maisels MJ, et al. Kernicterus: epidemiological strategies for its prevention through systems-based approaches. J Perinatol 2004;24:650-62.

4. Van Praagh R. Diagnosis of kernicterus in the neonatal period. Pediatrics 1961;28:870-4.

5. Jones $\mathrm{MH}$, Sands $\mathrm{R}$, Hyman $\mathrm{CB}$, et al. Longitudinal study of the incidence of central nervous system damage following erythroblastosis fetalis. Pediatrics 1954;14:346.

6. Perlstein M. Neurologic sequelae of erythroblastosis fetalis. Am J Dis Child 1950;79:605-6

7. Volpe JJ. Bilirubin and brain injury. In: Volpe JJ, editor. Neurology of the Newborn. 4th ed. Philadelphia, PA: W. B. Saunders Co.; 2001.

8. Bhutani VK, Johnson L, Keren R. Acute bilirubin encephalopathy... before it is too late. Contemp Pediatr 2005:54-74.

9. Bhutani VK, Johnson L. Kernicterus: a preventable neonatal brain injury. J Arab Neonatal Forum 2005 Available at: http://www.fmhs. uaeu.ac.ae/neonatal/iss003/pap03.asp. Accessed 8/2/08.

10. Ip S, Chung $M$, and the Subcommittee on Hyperbilirubinemia. An evidence-based review of important issues concerning neonatal hyperbilirubinemia. Pediatrics 2004;114:e130-53.

11. Hyperbilirubinemia in the neonate: risk assessment, screening and management, Association of Women's Health, Obstetrics and Neonatal Nurses. Available at: http://www.awhonn.org/awhonn/ product.detail.do?productCode=HNPP-CD-2NDI. Accessed 8/2/08.
12. Bhutani VK, Johnson L. Kernicterus in late preterm infants cared for as term healthy infants. Semin Perinatol 2006;30:89-97.

13. Keren R, Luan X, Friedman S, et al. A comparison of alternative risk-assessment strategies for predicting significant neonatal hyperbilirubinemia in term and near-term infants. Pediatrics 2008;121: el70-9.

14. Johnson LH, Bhutani VK. Guidelines for management of the jaundiced term and near-term infant. Clin Perinatol 1998;25: 555-74.

15. Wennberg RP, Ahlfors CE, Bhutani VK, et al. Toward understanding kernicterus: a challenge to improve the management of jaundiced newborns. Pediatrics 2006;117:474-85.

16. Johnson L, Brown AK, Bhutani V. BIND—a clinical score for bilirubin induced neurologic dysfunction in newborns. Pediatrics 1999;104: 746.

17. Shapiro SM. Definition of the clinical spectrum of kernicterus and bilirubin-induced neurologic dysfunction (BIND). J Perinatol 2005; 25:54-9.

18. Hansen TW. Acute management of extreme neonatal jaundicethe potential benefits of intensified phototherapy and interruption of enterohepatic bilirubin circulation. Acta Paediatr 1997;86: 843-6.

19. Hansen TW. Mechanisms of bilirubin toxicity: clinical implications. Clin Perinatol 2002;29:765-78.

20. Watchko JF. Kernicterus and the molecular mechanisms of bilirubininduced CNS injury in newborns. Neuromolecular Med 2006;8: 513-29.

21. Bhutani VK, Johnson LH, Keren R. Diagnosis and management of hyperbilirubinemia in the term neonate: for a safer first week. Pediatr Clin North Am 2004;51:843-61.

22. Smitherman H, Stark AR, Bhutani VK. Early recognition of neonatal hyperbilirubinemia and its emergent management. Semin Fetal Neonatal Med 2006;11:214-24.

23. Maisels MJ, McDonagh AF. Phototherapy for neonatal jaundice. N Engl J Med 2008;358:920-8.

24. Dennery PA, Seidman DS, Stevenson DK. Neonatal hyperbilirubinemia. N Engl J Med 2001;344:581-90

25. Sheridan SE. Testimony to the National Summit on Medical Errors and Patient Safety Research, Washington, DC, 11 September 2000. Available at: www.quic.gov/summit/wsheridan.htm (21 March 2003).

26. Sheridan SE. Parents of infants and children with kernicterus. J Perinatol 2005;25:227-8.

27. Joint Commission Accrediting Hospital Organizations (JCAHO). Revised guidance to help prevent kernicterus. Sentinel Event Alert 2004:31:1-2.

28. Bhutani VK, Donn SM, Johnson LH. Risk management of severe neonatal hyperbilirubinemia: to prevent kernicterus. Clin Perinatol 2005;32:125-39.

29. Blackmon LR, Fanaroff AA, Raju TN, et al. Research on prevention of bilirubin-induced brain injury and kernicterus: National Institute of Child Health and Human Development conference executive summary. 2003. Pediatrics 2004;114:229-33.

30. Center for Disease Control and Prevention. Jaundice/Kernicterus. http://www.cdc.gov/ncbddd/dd/kernichome.htm. Accessed 8/2/08. 